\title{
Effects of Varying Levels of Inspiratory Assistance with Pressure Support Ventilation and Neurally Adjusted Ventilatory Assist on Driving Pressure in Patients Recovering from Hypoxemic Respiratory Failure
}

\author{
Gianmaria Cammarota ${ }^{1,7}$ (D) Federico Verdina ${ }^{2} \cdot$ Nello De Vita $^{2} \cdot$ Ester Boniolo $^{2} \cdot$ Riccardo Tarquini $^{1}$. \\ Antonio Messina ${ }^{3} \cdot$ Marta Zanoni $^{1} \cdot$ Paolo Navalesi $^{4} \cdot$ Luigi Vetrugno $^{5}$ - Elena Bignami ${ }^{6}$. Francesco Della Corte ${ }^{2}$. \\ Edoardo De Robertis ${ }^{7} \cdot$ Erminio Santangelo $^{2} \cdot$ Rosanna Vaschetto $^{2}$
}

Received: 17 November 2020 / Accepted: 28 January 2021 / Published online: 9 February 2021

(c) The Author(s), under exclusive licence to Springer Nature B.V. part of Springer Nature 2021

\begin{abstract}
Background Driving pressure can be readily measured during assisted modes of ventilation such as pressure support ventilation (PSV) and neurally adjusted ventilatory assist (NAVA). The present prospective randomized crossover study aimed to assess the changes in driving pressure in response to variations in the level of assistance delivered by PSV vs NAVA.

Methods 16 intubated adult patients, recovering from hypoxemic acute respiratory failure (ARF) and undergoing assisted ventilation, were randomly subjected to six 30-min-lasting trials. At baseline, PSV (PSV100) was set with the same regulation present at patient enrollment. The corresponding level of NAVA (NAVA100) was set to match the same inspiratory peak of airway pressure obtained in PSV100. Therefore, the level of assistance was reduced and increased by 50\% in both ventilatory modes (PSV50, NAVA50; PSV150, NAVA150). At the end of each trial, driving pressure obtained in response to four short (2-3 s) end-expiratory and end-inspiratory occlusions was analyzed.

Results Driving pressure at PSV50 (6.6 [6.1-7.8] $\left.\mathrm{cmH}_{2} \mathrm{O}\right)$ was lower than that recorded at PSV100 (7.9 [7.2-9.1] $\mathrm{cmH}_{2} \mathrm{O}$, $P=0.005)$ and PSV150 (9.9 [9.1-13.2] $\left.\mathrm{cmH}_{2} \mathrm{O}, P<0.0001\right)$. In NAVA, driving pressure at NAVA50 was reduced compared to NAVA150 (7.7 [5.1-8.1] $\mathrm{cmH}_{2} \mathrm{O}$ vs 8.3 [6.4-11.4] $\left.\mathrm{cmH}_{2} \mathrm{O}, P=0.013\right)$, whereas there were no changes between baseline and NAVA150 (8.5 [6.3-9.8] $\mathrm{cmH}_{2} \mathrm{O}$ vs 8.3 [6.4-11.4] $\mathrm{cmH}_{2} \mathrm{O}, P=0.331$, respectively). Driving pressure at PSV150 was higher than that observed in NAVA150 $(P=0.011)$.

Conclusions NAVA delivers better lung-protective ventilation compared to PSV in hypoxemic ARF patients.

Trial registration number and date of registration The present trial was prospectively registered at www.clinicatrials.gov (NCT03719365) on 24 October 2018
\end{abstract}

Keywords Driving pressure $\cdot$ Neurally adjusted ventilatory assist $\cdot$ Pressure support ventilation

Gianmaria Cammarota and Federico Verdina equally contributed to the present investigation

Gianmaria Cammarota

gmcamma@gmail.com

1 Anesthesia and General Intensive Care, "Maggiore Della Carità” University Hospital, Novara, Italy

2 Department of Translational Medicine, Università del Piemonte Orientale, Novara, Italy

3 Humanitas Clinical and Research Center - IRCCS, Rozzano, Milan, Italy

4 Department of Medicine, University of Padua, Padova, Italy

5 Department of Medicine, Anesthesia and Intensive Care Clinic, Università Di Udine, Udine, Italy

6 Anesthesiology, Critical Care and Pain Medicine Division, Department of Medicine and Surgery, University of Parma, Parma, Italy

7 Department of Medicine and Surgery, Università Degli Studi Di Perugia, Perugia, Italy 


\section{Introduction}

Driving pressure is closely associated with outcome in acute respiratory distress syndrome (ARDS) patients requiring invasive mechanical ventilation (IMV) due to hypoxemic acute respiratory failure (ARF) [1]. In these conditions, high driving pressure is an independent risk factor for increased mortality during both controlled and assisted IMV [1, 2].

Recently, driving pressure computation has been obtained also in patients receiving neurally adjusted ventilatory assist (NAVA) after lung transplantation [3]. NAVA has been reported to ameliorate patient-ventilator synchrony because, compared to pressure support ventilation (PSV), it allows a better adaptation of the ventilator to patient's neural inspiratory timing, through neural trigger, and preserves a more physiological breathing pattern thanks to a proportional ventilatory assistance [4-7]. However, no data are available about driving pressure variations induced by different levels of assistance during NAVA. Gaining an in-depth understanding of the interplay between driving pressure and NAVA would have meaningful implications for those clinicians wishing to reduce the risk of ventilator-induced lung injury (VILI) during assisted IMV. VILI is highly dependent on the interaction between what is conveyed by the ventilator machine and the corresponding lung adaptation elicited in response to the ventilator action itself $[8,9]$. In this regard, being the ventilation a dynamic process, the role played by the respiratory rate in VILI determinism is equally important [10]. Mechanical power, by accounting for tidal volume, driving pressure, and respiratory rate at the same time, provides an estimation of the energy applied to the respiratory system per minute [11]. A high mechanical power is an independent risk factor for an increased mortality in patients undergoing IMV lasting $>48 \mathrm{~h}$ [12]. In intubated ARDS patients, an elastic mechanical power exceeding the threshold of $12 \mathrm{~J} \mathrm{~min}^{-1}$ has beean found to be associated with poor outcome [13].

The present prospective randomized crossover physiological study sought to primarily assess and compare driving pressure modifications at varying level of assistance during PSV vs NAVA in intubated hypoxemic ARF patients. As additional end-point, the numbers of patients exposed to non-protective ventilation-i.e., driving pressure $\geq 12$ $\mathrm{cmH}_{2} \mathrm{O}$ [2] and/or tidal volume $\left(\mathrm{V}_{\mathrm{T}}\right)>8 \mathrm{ml} \mathrm{kg}^{-1}$ —in both PSV and NAVA modes were computed and compared throughout the whole study duration. Secondarily, the mechanical energy [14] and power [13] applied through each ventilatory mode across all study steps were evaluated. Finally, the number of patients in whom mechanical power exceeded the threshold of $12 \mathrm{~J} \mathrm{~min}^{-1}$ was also computed over the entire study duration.

\section{Materials and methods}

\subsection{Patients}

A cohort of adult patients recovering from hypoxemic ARF and undergoing IMV lasting $>24 \mathrm{~h}$ in PSV mode was investigated according to the Helsinki Declaration, after obtaining informed consent. The protocol was approved by the local Ethics Committee (CE 110/18) and registered (www. clinicatrials.gov NCT03719365). Exclusion criteria were: acute brain injury, hemodynamic instability despite adequate filling - i.e., need for continuous infusion of epinephrine or vasopressin, dopamine $>5 \mu \mathrm{g} \mathrm{kg}^{-1} \mathrm{~min}^{-1}$ or norepinephrine $>0.1 \mu \mathrm{g} \mathrm{kg}^{-1} \mathrm{~min}^{-1}$ in order to maintain systolic arterial blood pressure $>90 \mathrm{mmHg}$, core temperature $>38^{\circ} \mathrm{C}$, contraindication to gastro-esophageal catheter positioning and pregnancy.

\subsection{Protocol}

After recording the electrical activity of the diaphragm (Eadi) signal through a dedicated feeding tube (Edi Catheter, Getinge, Sweden), as previously described [4], patients were randomly subjected to six 30-min-lasting trials (Fig. 1). Baseline PSV (PSV100)—i.e., positive end-expiratory pressure (PEEP) and pressure support over PEEP_—was the same as that adopted at patient enrolment, with the flow trigger set at the most sensitive level possible paying attention to avoid auto-triggers [4]. The expiratory cycle-off threshold was set at $30 \%$ of the inspiratory airflow peak. The corresponding baseline setting for NAVA (NAVA100) was chosen to provide an inspiratory airway pressure (Paw) peak equivalent to that obtained with PSV [5]. Thereafter, the level of assistance was reduced and increased in both PSV (PSV50, PSV150) and NAVA (NAVA50, NAVA150) modes, respectively. At the end of each 30-min trial, four short (2-3 s) end-expiratory and end-inspiratory occlusions were performed checking for adequate muscle relaxation, as judged by Eadi returning to baseline and by a flat and stable plateau in Paw tracing. The occlusions were performed at random intervals of 3-30 breaths between one occlusion and the subsequent hold [15].

\subsection{Measurements}

Airflow, Paw and Eadi were all acquired from the ventilator (Nava Tracker, Getinge, Sweden) and subjected to offline analysis (ICU-Lab, KleisTek, Bari, Italy). The following variables were obtained - and averaged — from the occlusions: driving pressure, Paw peak, $\mathrm{V}_{\mathrm{T}}$, Paw plateau, total PEEP, and Eadi peak. During offline analysis, pressure muscle index (PMI) $[3,16]$ and respiratory system compliance were 
Fig. 1 Study protocol. PSV pressure support ventilation, NAVA neurally adjusted ventilatory assist, $P S$ pressure support, $P a w_{\text {peak }}$ peak of airway pressure, PSV100 and NAVA100 baseline level of assistance in PSV and NAVA, PSV50 and NAVA50, level of assistance in PSV and NAVA decreased by $50 \%$ with respect to baseline, $P S V 150$ and NAVA150 level of assistance in PSV and NAVA increased by $50 \%$ with respect to baseline
PSV Baseline

PEEP and PS over PEEP at enrollment

NAVA Baseline

NAVA level to match the same Paw peak $_{\text {of }}$ PSV Baseline; PEEP same as that of PSV Baseline

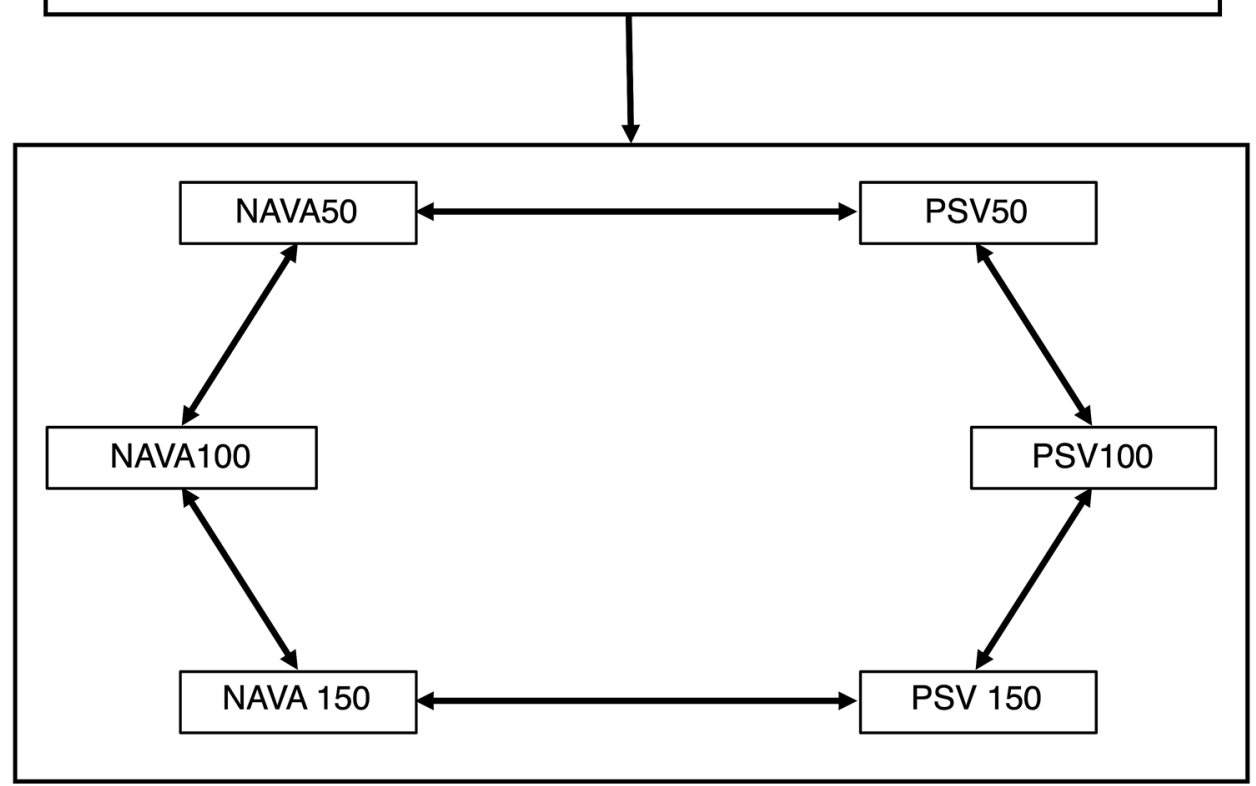

computed. Also, the elastic mechanical energy [14] applied per breath and elastic mechanical power [13], assessed in quasi-static conditions, were computed according to the following formulas:

Mechanical energy per breath $(J)=$ driving pressure $\times V_{T}$

Mechanical power $(\mathrm{J} / \mathrm{min})=$ driving pressure $\times \mathrm{V}_{\mathrm{T}} \times$ respiratory rate

\subsection{Statistical analysis}

A sample size of 16 patients was deemed suitable to observe a driving pressure median difference of $2 \mathrm{cmH}_{2} \mathrm{O}$ [2] in NAVA vs PSV $(\alpha 0.017 ; \alpha 0.20)$.

Data were expressed as median and 25th-75th percentile values unless otherwise specified. All continuous variables were compared between modes. The effects of the two modes were first assessed by Friedman test and then by the Wilcoxon signed-rank text trough Bonferroni correction for multiple comparisons $(P<0.017)$. The categorical variables comparison was conducted through Fisher's exact test. Also in this case, we considered a two-sided $P<0.017$ significant. Statistical analysis was performed by MedCalc 13.0 (MedCalc Software bvba).

\section{Results}

From May 2019 to July 2020, as reported in Table 1, 14 selected intubated hypoxemic ARF patients were enrolled after a median IMV duration of 5 (3-10) days.

At study entry, arterial pH was 7.45 [7.42-7.46], arterial carbon dioxide tension was 45.6 [41.9-47] $\mathrm{mmHg}$, and arterial oxygen tension to inspired oxygen fraction ratio was 229 [210-256] $\mathrm{mmHg}$ in presence of an inspired oxygen fraction of 0.40 [0.36-0.50]. At baseline, PEEP was $10(10-12)$ $\mathrm{cmH}_{2} \mathrm{O}$, pressure support over PEEP was 7 (5-8) $\mathrm{cmH}_{2} \mathrm{O}$

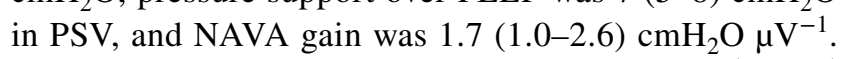
Minute ventilation was $122.1(98.5-148.5) \mathrm{ml} \mathrm{kg}^{-1} \mathrm{~min}^{-1}$ in PSV and $132.6(107.7-156.6) \mathrm{ml} \mathrm{kg}^{-1} \mathrm{~min}^{-1}$ in NAVA $(P=0.298)$.

Table 2 lists patient-ventilator interaction for PSV and NAVA, respectively. In PSV-assisted patients where the ventilatory support had been reduced by $50 \%$, driving pressure was significantly lower than that recorded at PSV 100 and PSV150 ( $P=0.005$ and $P<0.0001$, respectively). When patients were assisted through NAVA under similar conditions, driving pressure was only reduced with respect to NAVA150 (NAVA50 vs NAVA150, $P=0.013$ ) but not baseline. Importantly, when the ventilatory support was increased by $50 \%$ over baseline, driving pressure was higher in PSV 
Table 1 Patients characteristics at enrollment

\begin{tabular}{|c|c|c|c|c|c|c|c|c|}
\hline Patients & Gender & Age (years) & PBW (kg) & BMI $\left(\mathrm{kg} \mathrm{m}^{-2}\right)$ & Admission diagnosis & Days of IMV & $\operatorname{PEEP}\left(\mathrm{cmH}_{2} \mathrm{O}\right)$ & $\begin{array}{l}\text { PS over } \\
\operatorname{PEEP}\left(\mathrm{cmH}_{2} \mathrm{O}\right)\end{array}$ \\
\hline 1 & $\mathrm{~F}$ & 78 & 57 & 47.8 & Pneumonia & 11 & 10 & 8 \\
\hline 2 & $\mathrm{~F}$ & 64 & 52 & 21.5 & ARDS & 5 & 10 & 8 \\
\hline 3 & M & 66 & 84 & 38.5 & Polytrauma & 11 & 12 & 4 \\
\hline 4 & M & 54 & 72 & 31.9 & Pneumonia & 10 & 10 & 7 \\
\hline 5 & M & 77 & 66 & 27.7 & Pneumonia & 8 & 10 & 5 \\
\hline 6 & M & 55 & 75 & 24.7 & ARDS & 4 & 10 & 5 \\
\hline 7 & M & 83 & 66 & 26.0 & Pneumonia & 1 & 12 & 3 \\
\hline 8 & $\mathrm{~F}$ & 60 & 52 & 58.0 & ARDS & 5 & 9 & 13 \\
\hline 9 & M & 83 & 66 & 24.2 & Pneumonia & 3 & 14 & 7 \\
\hline 10 & M & 65 & 66 & 24.2 & Airway bleeding & 7 & 10 & 5 \\
\hline 11 & M & 59 & 75 & 30.9 & Thoracic trauma & 11 & 14 & 6 \\
\hline 12 & M & 71 & 73 & 31.6 & Cardiac arrest & 9 & 10 & 8 \\
\hline 13 & $\mathrm{~F}$ & 77 & 48 & 33.3 & Peritonitis & 1 & 10 & 7 \\
\hline 14 & M & 61 & 70 & 33.3 & Pneumonia & 5 & 12 & 6 \\
\hline 15 & M & 42 & 71 & 27.8 & Polytrauma & 4 & 10 & 6 \\
\hline 16 & $\mathrm{~F}$ & 56 & 48 & 16.6 & Pneumonia & 3 & 8 & 7 \\
\hline Overall & $5 \mathrm{~F} / 11 \mathrm{M}$ & $65(57-77)$ & $66(53-73)$ & $\begin{array}{l}31.2(25.0- \\
37.2)\end{array}$ & & $5(3-10)$ & $10(10-12)$ & $7(5-8)$ \\
\hline
\end{tabular}

The frequency of distribution and the median and $\left[25^{\text {th }}, 75^{\text {th }}\right.$ percentile $]$ are reported in the bottom line

$M$ male, $F$ female, $P B W$ predicted body weight, $B M I$ body mass index, $A R D S$ acute respiratory distress syndrome, $I M V$ invasive mechanical ventilation, PEEP positive end-expiratory pressure, $P S$ over PEEP pressure support over PEEP

than in NAVA $(P=0.011)$. Paw peak and $\mathrm{V}_{\mathrm{T}}$ were both lower at PSV50 vs PSV100 $(P=0.005$ and $P=0.008$, respectively $)$ and at PSV100 vs PSV150 $(P=0.005$ and $P=0.008$, respectively). Paw peak and $V_{T}$ at PSV150, were much greater than those measured at PSV50 $(P<0.0001$ for all comparisons). In NAVA, both Paw peak and $\mathrm{V}_{\mathrm{T}}$ reached higher levels than those at NAVA50 $(P<0.0001$ and $P<0.001)$ only when the ventilatory assistance was increased to NAVA150. At PSV150, $\mathrm{V}_{\mathrm{T}}$ was higher than that observed at the same level of assistance in NAVA $(P=0.003)$. Paw plateau was reduced at PSV 50 vs both baseline $(P=0.002)$ and PSV150 $(P<0.0001)$. During NAVA, Paw plateau at NAVA50 was only lower with respect to NAVA150 $(P=0.008)$ but not baseline. Furthermore, at PSV150 Paw plateau was higher than that measured at NAVA150 $(P=0.011)$. In PSV, PMI at PSV50 was higher than that measured at baseline $(P=0.008)$ and PSV150 $(P<0.0001)$. In NAVA, PMI increased moving from NAVA150 to NAVA50 $(P<0.001)$ and from NAVA150 to baseline $(P=0.008)$. No significant modifications were observed regarding respiratory system compliance throughout the entire study duration. Eadi peak increased while changing the level of assistance from PSV150 to PSV50 $(P<0.0001)$, while no variations were detected in NAVA. Elastic mechanical energy per breath increased from PSV50 to baseline $(P=0.003)$ and from baseline to PSV150 $(P=0.013)$. Always in PSV, elastic mechanical energy per breath was higher at PSV150 than at PSV50 $(P<0.0001)$. In NAVA, elastic mechanical energy per breath increased at NAVA150 compared to -NAVA50 $(P<0.001)$. Only at PSV150, elastic mechanical energy per breath was greater compared to that computed at the same level of assistance in NAVA $(P=0.006)$. Mechanical respiratory rate diminished while switching from PSV50 to PSV150 ( $\mathrm{p}<0.0001)$; at PSV150, mechanical respiratory rate was lower than that observed at the same level of assistance in NAVA $(\mathrm{p}<0.001)$. Total PEEP was not different between ventilatory modes across all study steps.

Figure 2 shows the numbers of patients experiencing a driving pressure $\geq 12 \mathrm{cmH}_{2} \mathrm{O}$ and/or $\mathrm{V}_{\mathrm{T}}>8 \mathrm{ml} \mathrm{kg}^{-1}$ across all study phases. Driving pressure was $\geq 12 \mathrm{cmH}_{2} \mathrm{O}$ in a similar number of patients undergoing PSV or NAVA over the whole duration of the study (Fig. 2a-c). At baseline (Fig. 2e) and at reduced level of assistance (Fig. 2d), no differences were detected between PSV and NAVA in the number of patients with $\mathrm{V}_{\mathrm{T}}>8 \mathrm{ml} \mathrm{kg} \mathrm{m}^{-1}$. Conversely, at increased level of assistance (Fig. 2f), $V_{\mathrm{T}}$ was $>8 \mathrm{ml} \mathrm{kg}^{-1}$ in 11 patients during PSV vs 3 patients during NAVA $(P=0.011)$.

Figure 3 depicts elastic mechanical power at varying level of assistance for PSV and NAVA. While increasing the level of assistance (Fig. 3a), elastic mechanical power increased from PSV50 to baseline [3.9 (2.9-5.2) vs 5.9 (4.7-6.8) $\left.\mathrm{J} \mathrm{min}^{-1}, P=0.005\right]$ and from PSV50 to PSV150 
Table 2 Patient-ventilator interaction

\begin{tabular}{|c|c|c|c|c|c|c|c|c|}
\hline \multirow[t]{2}{*}{ Variables } & \multicolumn{8}{|l|}{ Study steps } \\
\hline & PSV50 & PSV100 & PSV150 & $P$ values & NAVA50 & NAVA100 & NAVA150 & $P$-values \\
\hline $\begin{array}{l}\text { Driving pres- } \\
\text { sure, } \mathrm{cmH}_{2} \mathrm{O}\end{array}$ & $6.6[6.1-7.8]^{\dagger, \star}$ & $7.9[7.2-9.1]$ & $9.9[9.1-13.2]^{*}$ & $<0.0001$ & $7.7[5.1-8.1]^{\S}$ & $8.5[6.3-9.8]$ & $8.3[6.4-11.4]$ & 0.043 \\
\hline $\begin{array}{l}\text { Paw peak, } \\
\mathrm{cmH}_{2} \mathrm{O}\end{array}$ & $\begin{array}{c}13.6[12.5- \\
14.7]^{\dagger, \sharp}\end{array}$ & $\begin{array}{l}16.4[15.3- \\
17.8]\end{array}$ & $\begin{array}{l}19.5[17.6- \\
21.2]^{\dagger}\end{array}$ & $<0.0001$ & $\begin{array}{l}13.9[12.9- \\
7.2]^{\ddagger}\end{array}$ & $\begin{array}{l}17.2[15.2- \\
19.4]\end{array}$ & $\begin{array}{l}18.3[15.4- \\
21.3]\end{array}$ & $<0.0001$ \\
\hline $\mathrm{V}_{\mathrm{T}}, \mathrm{ml} \mathrm{kg}^{-1}$ & $5.6[4.7-7.4]^{\dagger \dagger, \ddagger}$ & $7.0[5.8-8.5]$ & $\begin{array}{l}8.9[7.9- \\
12.7]^{* *, \dagger \dagger}\end{array}$ & $<0.0001$ & $6.3[5.3-7.4]^{\ddagger \ddagger}$ & $7.1[5.3-7.8]$ & 7.4 [5.7-9.5] & 0.003 \\
\hline $\begin{array}{l}\text { Paw plateau, } \\
\mathrm{cmH}_{2} \mathrm{O}\end{array}$ & $\begin{array}{c}18.1[16.3- \\
21.0]^{\S \S, \leftarrow}\end{array}$ & $\begin{array}{l}19.4[17.8- \\
22.3]\end{array}$ & $\begin{array}{l}21.4[19.8- \\
24.3]^{*}\end{array}$ & $<0.0001$ & $\begin{array}{c}18.1[16.2- \\
21.8]^{\dagger \dagger}\end{array}$ & $\begin{array}{l}19.8[17.9- \\
22.4]\end{array}$ & $\begin{array}{l}20.3[16.8- \\
23.5]\end{array}$ & 0.023 \\
\hline $\mathrm{PMI}, \mathrm{cmH}_{2} \mathrm{O}$ & $3.8[3.2-6.3]^{\dagger \dagger, \ddagger}$ & $1.9[1.3-4.5]$ & $1.1[-0.2-4.0]$ & $<0.0001$ & $3.9[1.3-6.7]^{+\neq}$ & $2.7[-0.0-4.8]$ & $1.9[-0.7-3.7]^{\dagger \dagger}$ & $<0.001$ \\
\hline 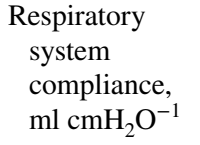 & $\begin{array}{l}56.6[39.8- \\
69.1]\end{array}$ & $\begin{array}{l}62.5[41.0- \\
72.6]\end{array}$ & $\begin{array}{l}61.6[42.8- \\
72.5]\end{array}$ & 0.646 & $\begin{array}{l}54.6[42.3- \\
66.6]\end{array}$ & $\begin{array}{l}56.6[39.5- \\
70.8]\end{array}$ & $\begin{array}{l}57.6[43.9- \\
69.5]\end{array}$ & 0.368 \\
\hline $\begin{array}{l}\text { Peak of Eadi, } \\
\mu \mathrm{V}\end{array}$ & $8.9[2.5-11.7]^{\frac{1}{+}}$ & $4.9[2.3-6.8]$ & 3.0 [1.3-7.7] & $<0.001$ & $5.0[3.0-8.5]$ & $5.5[3.6-8.0]$ & $4.2[2.9-9.1]$ & 0.174 \\
\hline $\begin{array}{l}\text { Mechanical } \\
\text { energy per } \\
\text { breath, J }\end{array}$ & $\begin{array}{r}0.2[0.2- \\
0.3]^{\S \S \S, \text { \# }}\end{array}$ & $0.4[0.3-0.5]$ & $\begin{array}{l}0.6[0.5- \\
0.8]^{+1}+{ }^{+} * * *\end{array}$ & $<0.0001$ & $0.2[0.2-0.4]^{\ddagger \ddagger}$ & $0.4[0.2-0.5]$ & $0.4[0.3-0.6]$ & 0.002 \\
\hline $\begin{array}{l}\text { Mechanical res- } \\
\text { piratory rate, } \\
\text { breaths } \text { min }^{-1}\end{array}$ & $\begin{array}{c}16.5[13.5- \\
18.8]^{\ddagger}\end{array}$ & $\begin{array}{l}14.5[13.0- \\
18.8]\end{array}$ & $\begin{array}{c}12.0[11.0- \\
5.8]^{* * * *}\end{array}$ & $<0.0001$ & $\begin{array}{l}15.5[14.0- \\
21.8]\end{array}$ & $\begin{array}{l}17.0[13.0- \\
19.0]\end{array}$ & $\begin{array}{l}16.5[13.3- \\
21.5]\end{array}$ & 0.532 \\
\hline
\end{tabular}

Data are presented as median and [25th,75th percentile]. $P$ values derive from non-parametric Friedman's test for repeated measures, whereas symbols refer to $P$-values from multiple comparison post-hoc

${ }^{*} P=0.011$ PSV vs NAVA at equivalent level of assistance, ${ }^{\dagger} P=0.005$ vs baseline of the same ventilation mode, ${ }^{\ddagger} P<0.0001$ vs increased level of assistance of the same ventilation mode,${ }^{\S} P=0.013$ vs increased level of assistance of the same ventilation mode, ${ }^{* *} P=0.003$ PSV vs NAVA at equivalent level of assistance, ${ }^{\dagger \dagger} P=0.008$ vs baseline of the same ventilation mode, ${ }^{\sharp} P<0.001$ vs increased level of assistance of the same ventilation mode, ${ }^{\S \S} P=0.002$ vs baseline of the same ventilation mode, ${ }^{* * *} P=0.006$ PSV vs NAVA at equivalent level of assistance; ${ }^{\dagger \dagger \dagger} P=0.008$ vs increased level of assistance of the same ventilation mode, ${ }^{+} P=0.013$ vs baseline of the same ventilation mode, ${ }^{\$ \S \S} P=0.003$ vs baseline of the same ventilation mode, ${ }^{* * * *} P<0.001$ PSV vs NAVA at equivalent level of assistance. PSV50 and NAVA50, level of assistance in PSV and NAVA decreased by 50\% with respect to baseline; PSV100 and NAVA100, baseline level of assistance in PSV and NAVA; PSV150 and NAVA150, level of assistance in PSV and NAVA increased by $50 \%$ with respect to baseline

$P S V$ pressure support ventilation mode, NAVA neurally adjusted ventilatory assist mode, $P a w$ airway pressure, $V_{T}$ tidal volume on predicted body weight, $P M I$ pressure muscle index, $P E E P$ positive end-expiratory pressure, Eadi electrical activity of the diaphragm

[3.9 (2.9-5.2) vs $\left.7.5(6.1-9.9) \mathrm{J} \mathrm{min}^{-1}, P<0.0001\right]$, respectively. In NAVA (Fig. 3b), elastic mechanical power was higher at NAVA150 compared to NAVA50 [6.7 (4.4-10.4) vs 4.5 (3.6-5.4) $\left.\mathrm{J} \mathrm{min}^{-1}, P=0.005\right]$ without modifications with respect to baseline [NAVA150 vs baseline, 6.7 (4.4-10.4) vs $6.1(5.2-7.5) \mathrm{J} \mathrm{min}^{-1}$ and NAVA50 vs baseline, 4.5 (3.6-5.4) vs $6.1(5.2-7.5) \mathrm{J} \mathrm{min}^{-1}, P=0.157$ for all comparisons]. No differences in elastic mechanical power were detected between PSV and NAVA throughout the whole study duration. The number of patients in whom elastic mechanical power was greater than $12 \mathrm{~J} \mathrm{~min}^{-1}$ was similar between NAVA and PSV at reduced level of assistance [1 (6.3\%) vs $0(0.0 \%), P>0.999$ ], baseline [0 $(0.0 \%)$ vs $0(0.0 \%), P>0.999]$, and at increased level of assistance [2 (12.5\% vs 3 (18.8\%), $P>0.999$ ], respectively.

\section{Discussion}

Our findings indicate that, at increased levels of assistance, NAVA provides better lung-protective ventilation in comparison with PSV thanks to the lower driving pressure and $\mathrm{V}_{\mathrm{T}}$ generated by the former mode. In good agreement, NAVA but not PSV allowed $V_{T}$ self-regulation within a protective range despite increasing ventilatory assistance in hypoxemic ARF patients [17]. NAVA-mediated lung protection is thought to rely on the two following physiological mechanisms: (1) the downregulation of central respiratory output during lung overdistention [18]; and (2) the decrease in diaphragmatic effort as a consequence of an impaired pressure-generating capacity with increasing lung volume [19]. When we raised the level of assistance in our patients, we overall recorded median driving pressure values below the "safety threshold" recently proposed in patients recovering from ARDS [2], during both NAVA and PSV. However, 

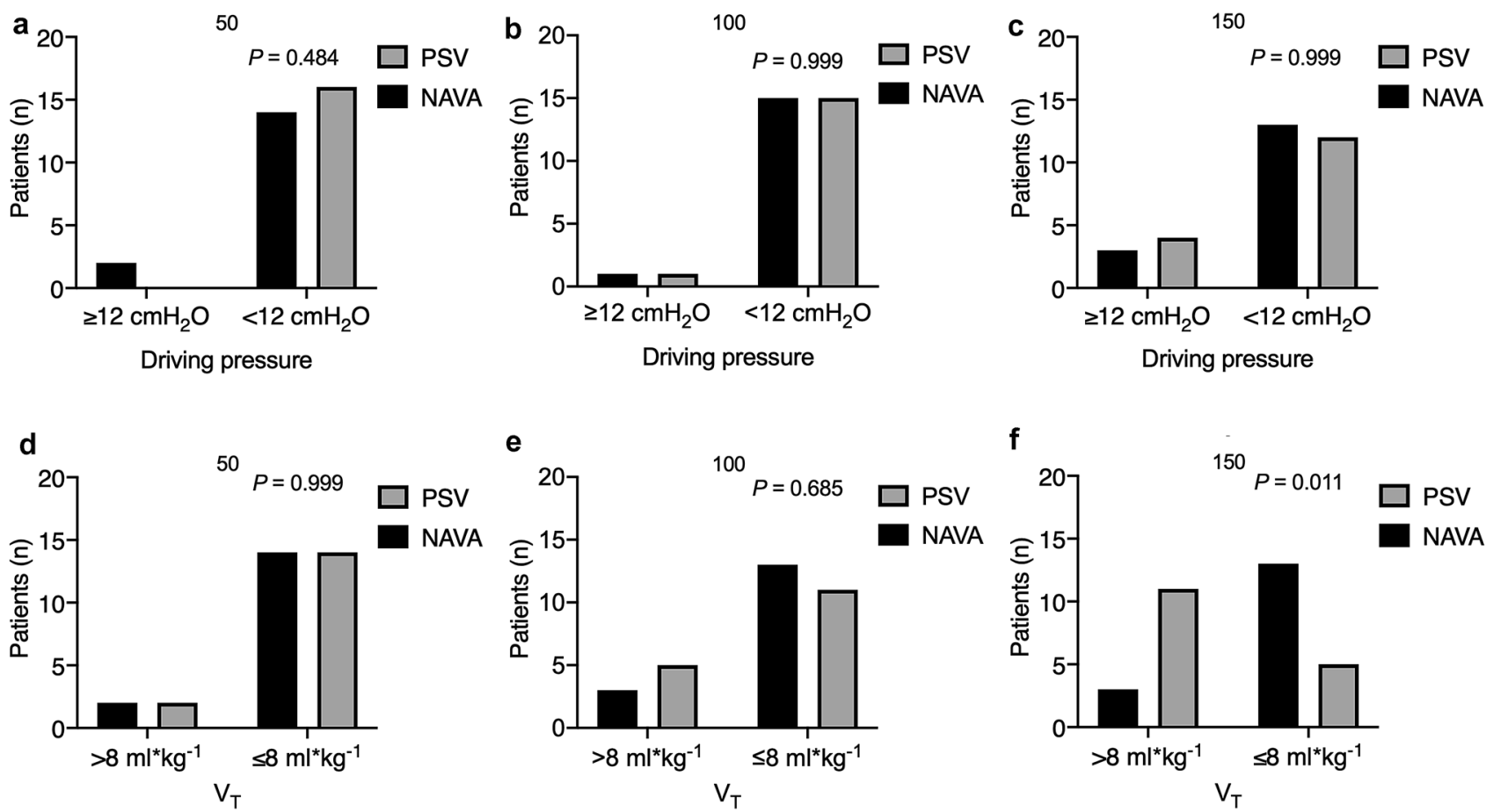

Fig. 2 Driving pressure and tidal volume at varying level of assistance. The number of patients with driving pressure $\geq 12 \mathrm{cmH}_{2} \mathrm{O}$ and $<12 \mathrm{cmH}_{2} \mathrm{O}$ are plotted at a level of assistance reduced by $50 \%$ with respect to baseline (a), baseline (b), and at a level of assistance increased by $50 \%$ with respect to baseline (c) in PSV (grey bars) and NAVA (black bars). The number of patients with tidal volume
$\left(\mathrm{V}_{\mathrm{T}}\right)>8 \mathrm{ml} \mathrm{kg}-1$ and $\leq 8 \mathrm{ml}^{*} \mathrm{~kg}^{-1}$ are plotted at a level of assistance reduced by $50 \%$ with respect to baseline (d), at baseline (e), and at a level of assistance increased by $50 \%$ with respect to baseline (f) in PSV (grey bars) and NAVA (black bars). $P$-values refer to Fisher's Exact text. $P S V$ pressure support ventilation, $N A V A$ neurally adjusted ventilatory assist

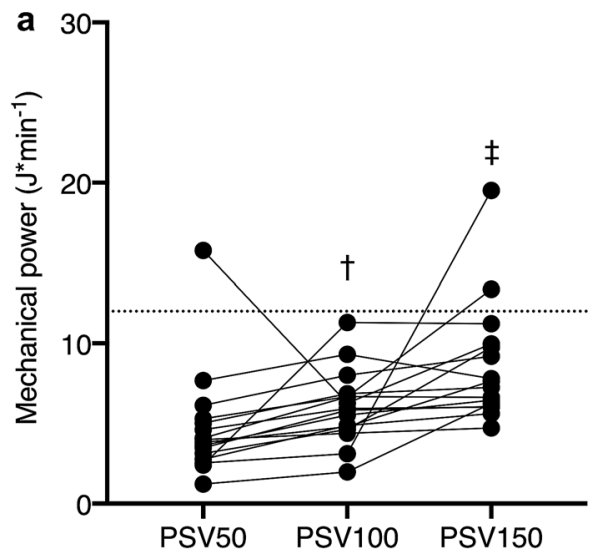

Fig. 3 Elastic mechanical power at varying level of assistance. Elastic mechanical power is plotted for each single patient at varying level of assistance for PSV (a) and NAVA (b). PSV, solid circles; NAVA, hollow circles. PSV100 and NAVA100, baseline level of assistance in PSV and NAVA; PSV50 and NAVA50, level of assistance in PSV and NAVA decreased by $50 \%$ with respect to baseline; PSV150 and NAVA150, level of assistance in PSV and NAVA increased by $50 \%$

always at high level of assistance, the median driving pressure and the number of patients exposed to $\mathrm{V}_{\mathrm{T}}>8 \mathrm{ml} \mathrm{kg}^{-1}$ were higher in PSV than in NAVA, indicating that NAVA

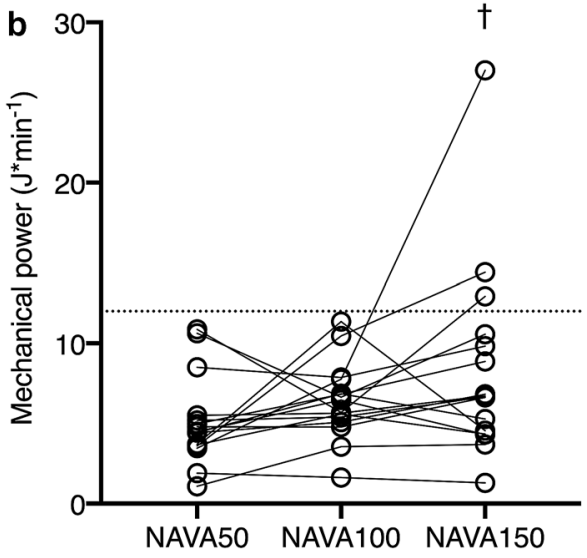

with respect to baseline. Dotted line corresponds to elastic mechanical power threshold $=12 \mathrm{~J}^{*} \mathrm{~min}^{-1}$. Symbols refer to $P$ values deriving from Friedman's test and post hoc analysis: ${ }^{\dagger}$ vs reduced level of assistance, $P=0.005$; ${ }^{\star}$ vs reduced level of assistance, $P<0.0001$. $P S V$ pressure support ventilation, $N A V A$ neurally adjusted ventilatory assist

delivers better lung-protective ventilation in intubated ARF patients. It is worth to point out that driving pressure accounts for $\mathrm{V}_{\mathrm{T}}$ and respiratory system compliance at the 
same time [1]. Accordingly, under conditions lacking respiratory system properties modifications, such as in our trials, the more marked increase in driving pressure observed in PSV vs NAVA can be explained by a greater $V_{T}$ provided at higher levels of assistance.

In our series, once again at high level of assistance, the better lung-protective ventilation provided by NAVA was associated with a lower elastic mechanical energy applied per breath to the respiratory system with respect to PSV. Being elastic mechanical energy per breath, measured in quasi-static conditions, directly dependent on $\mathrm{V}_{\mathrm{T}}$ and driving pressure at the same time $[14,20]$, it's easy to realize that when these two variables are increased, as it was in our setting at high level of assistance, the respiratory system is consistently subjected to an increased amount of elastic mechanical energy. Contrariwise, elastic mechanical power was not different between the two ventilatory modes, albeit it increased at high level of assistance compared to previous steps. As a matter of fact, elastic mechanical power accounts for $\mathrm{V}_{\mathrm{T}}$, driving pressure, and respiratory rate at the same time $[13,20]$. Thus, in our setting, the rising of elastic mechanical power observed at high level of assistance was due to different phenomena: (1) the increase of $\mathrm{V}_{\mathrm{T}}$ and driving pressure in PSV and (2) the high respiratory rate in NAVA, respectively. These findings are in good agreement with previous investigations demonstrating that both $\mathrm{V}_{\mathrm{T}}$ and driving pressure [21-26] as well as respiratory rate [27] play an important role either in the rise of mechanical power and in the development of lung injury during IMV. As a clinical implication, our findings may be clinically relevant in the perspective of VILI prevention in intubated patients undergoing assisted ventilation while recovering from hypoxemic ARF.

One of the limitations of this single-center investigation is represented by the limited size of our study sample that, despite being deemed sufficient enough to observe a driving pressure median difference of $2 \mathrm{cmH}_{2} \mathrm{O}$ [2] between NAVA and PSV at different levels of assistance, does not allow definitive conclusions to be drawn. Our patients were highly selected because the enrollment was conditioned by the presence of highly skilled physician in NAVA ventilation. Patients enrollment was interrupted from the end of February to May 2020 because of the disease due to novel coronavirus' 19 outbreak and subsequently resumed in June of the same year [28]. PSV setting at baseline was the same as that observed at patients' enrollment, with a combination of PEEP, inspired oxygen fraction, and inspiratory pressure support over PEEP set, according to our routine clinical practice, to preserve $\mathrm{pH}$ and arterial carbon dioxide tension within a physiologic range and to maintain a peripheral oxygen saturation between 92 and 96\% [29-31]. However, setting PSV at baseline as in our case might put patients at risk for lung overdistention when the threshold of $8 \mathrm{ml} \mathrm{kg}^{-1}$ is exceeded during assisted breath. The elastic mechanical energy and power were computed in quasi-static condition according to formula employed in course of controlled ventilation $[13,14,20]$. If, on the one hand, these computations refer to the elastic energy and power applied to the respiratory system, on the other hand they miss to account for the resistive component and the PEEP contribution. As a matter of fact, driving pressure and $\mathrm{V}_{\mathrm{T}}$ are pointed by clinical data as key variables for VILI [1, 9]. Hence, here we can provide only a partial computation of the energy and power expenditure in our patients during assisted ventilation. In addition, always in reference to computation of the energy and power, we used the driving pressure applied to the respiratory system overall and not the tidal transpulmonary pressure variation [32]. Consequently, in our patients, we could not describe the real energy and power to which the lung was subjected in each patient. Also, we were not able to show the global impact of patient's inspiratory effort on the lung at varying of inspiratory assistance during the trial. To this end, an advanced respiratory monitoring-i.e., esophageal pressure or electrical impedance tomography - may help in assessing the stress and gas distribution (pendelluft) on the dependent and non-dependent lung regions during assisted and spontaneous breath, as previously reported [33, 34]. Furthermore, 7 of the 16 hypoxemic ARF patients enrolled in this study received IMV because of pneumonia. Thus, our results await further confirmation in larger and multicenter investigations designed to evaluate the lung-protective function of NAVA in a specific subset of patients recovering from ARDS.

\section{Conclusions}

Overall, the present physiological investigation shows that, at high levels of assistance, NAVA delivers a more effective lung-protective ventilation compared to PSV by maintaining a lower driving pressure, avoiding lung overdistention, and applying a lower elastic mechanical energy per breath to the respiratory system. Conversely, the two ventilatory modes developed the same elastic mechanical power, regardless of the level of ventilatory assistance.

Acknowledgements The authors wish to thank all the staff of the intensive care unit for their contributions to the present study.

Funding Support was provided solely from hospital sources.

Data Availability The data of the present trial will be available on specific request sent to gmcamma@gmail.com. 


\section{Compliance with Ethical Standards}

Conflict of interest Dr. Antonio Messina declares to have received personal fees for services provided, as well as other benefits, from Vygon, but which were in no way related to the submitted work.

Prof. Paolo Navalesi declares to have received: grants, personal fees and non-financial support from Maquet Critical Care-Getinge; grants and non-financial support from Draeger and Intersurgical S.p.A; and personal fees from Oriopharma, Philips, Resmed, MSD, and Novartis, in each case for reasons that remain unrelated to the submitted work. Prof. Navalesi also contributed to the development of the patented 'helmet Next', the royalties for which are paid to Intersurgical Spa. Prof. Navalesi contributed to the development of a device not discussed in the present study with patent application number: EP20170199831. The other Authors declares no conflict of interest.

Ethical Approval The present investigation was approved by Ethical Committee of Azienda Ospedaliero-Universitaria "Maggiore della Carità"- Novara, Italy (protocol No. CE 110/18).

\section{References}

1. Amato MBP, Meade MO, Slutsky AS, Brochard L, Costa ELV, Schoenfeld DA, et al. Driving pressure and survival in the acute respiratory distress syndrome. N Engl J Med. 2015;372:747-55.

2. Bellani G, Grassi A, Sosio S, Gatti S, Kavanagh BP, Pesenti A, et al. Driving pressure is associated with outcome during assisted ventilation in acute respiratory distress syndrome. Anesthesiology. 2019;131:594-604.

3. Grasselli G, Castagna L, Abbruzzese C, Corcione N, Colombo SM, Guzzardella A, et al. Assessment of airway driving pressure and respiratory system mechanics during Neurally Adjusted Ventilatory Assist. Am J Respir Crit Care Med. 2019;200:785-8.

4. Colombo D, Cammarota G, Bergamaschi V, De Lucia M, Della CF, Navalesi P. Physiologic response to varying levels of pressure support and neurally adjusted ventilatory assist in patients with acute respiratory failure. Intensive Care Med. 2008;34:2010-8.

5. Cammarota G, Verdina F, Lauro G, Boniolo E, Tarquini R, Messina A, et al. Neurally adjusted ventilatory assist preserves cerebral blood flow velocity in patients recovering from acute brain injury. Dordrecht: Springer; 2020.

6. Vaschetto R, Cammarota G, Colombo D, Longhini F, Grossi F, Giovanniello A, et al. Effects of propofol on patient-ventilator synchrony and interaction during pressure support ventilation and neurally adjusted ventilatory assist. Crit Care Med. 2014;42:74-82.

7. Bruni A, Garofalo E, Pelaia C, Messina A, Cammarota G, Murabito $\mathrm{P}$, et al. Patient-ventilator asynchrony in adult critically ill patients. Minerva Anestesiol. 2019;85.

8. Beitler JR, Malhotra A, Thompson BT. Ventilator-induced lung injury. Clin Chest Med. 2016;37:633-46.

9. Pinhu L, Whitehead T, Evans T, Griffiths M. Ventilator-associated lung injury. Lancet. 2003;361:332-40.

10. Marini JJ, Rocco PRM, Gattinoni L. Static and dynamic contributors to ventilator-induced lung injury in clinical practice: pressure, energy, and power. Am J Respir Crit Care Med. 2020;201:767-74.

11. Rocco PRM, Silva PL, Samary CS, Hayat Syed MK, Marini JJ. Elastic power but not driving power is the key promoter of ventilator-induced lung injury in experimental acute respiratory distress syndrome. Crit Care Crit Care. 2020;24:1-8.
12. Serpa Neto A, Deliberato RO, Johnson AEW, Bos LD, Amorim $\mathrm{P}$, Pereira SM, et al. Mechanical power of ventilation is associated with mortality in critically ill patients: an analysis of patients in two observational cohorts. Intensive Care Med. 2018;44:1914-22.

13. Guérin C, Papazian L, Reignier J, Ayzac L, Loundou A, Forel JM. Effect of driving pressure on mortality in ARDS patients during lung protective mechanical ventilationin two randomized controlled trials. Crit Care. 2016;20:1-9.

14. Marini JJ, Jaber S. Dynamic predictors of VILI risk: beyond the driving pressure. Intensive Care Med. 2016;42:1597-600.

15. Younes M, Webster K, Kun J, Roberts D, Masiowski B. A method for measuring passive elastance during proportional assist ventilation. AJRCCM. 2001;164:50-60.

16. Foti G, Cereda M, Banfi G, Pelosi P, Fumagalli R, Pesenti A. End-inspiratory airway occlusion: a method to assess the pressure developed by inspiratory muscles in patients with acute lung injury undergoing pressure support. Am J Respir Crit Care Med. 1997;156:1210-6.

17. Carteaux G, Cordoba-Izquierdo A, Lyazidi A, Heunks L, Thille AW, Brochard L. Comparison between neurally adjusted ventilatory assist and pressure support ventilation levels in terms of respiratory effort. Crit Care Med. 2016;44:503-11.

18. Sinderby C, Beck J, Spahija J, De Marchie M, Lacroix J, Navalesi $\mathrm{P}$, et al. Inspiratory muscle unloading by neurally adjucted ventilatory assist during maximal inspiratory efforts in healthy subjects. Am Coll Chest Phys. 2007;131:711-7.

19. Beck J, Sinderby C, Lindström L, Grassino A. Effects of lung volume on diaphragm EMG signal strength during voluntary contractions. J Appl Physiol. 1998;85:1123-34.

20. Silva PL, Ball L, Rocco PRM, Pelosi P. Power to mechanical power to minimize ventilator-induced lung injury? Intensive Care Med Exp. 2019;7:1-11.

21. Bellani G, Laffey JG, Pham T, Fan E, Brochard L, Esteban A, et al. Epidemiology, patterns of care, and mortality for patients with acute respiratory distress syndrome in intensive care units in 50 countries. JAMA. 2016;315:788-800.

22. Network TARDS. Ventilation with lower tidal volumes as compared with traditional tidal volumes for acute lung injury and the acute respiratory distress syndrome. $\mathrm{N}$ Engl $\mathrm{J}$ Med. 2000;342:1301-8.

23. Neto AS, Hemmes SNT, Barbas CSV, Beiderlinden M, Fernandez-Bustamante A, Futier E, et al. Association between driving pressure and development of postoperative pulmonary complications in patients undergoing mechanical ventilation for general anaesthesia: a meta-analysis of individual patient data. Lancet Respir Med. 2016;4:272-80.

24. Briel M, Meade M, Mercat A. Higher vs lower positive endexpiratory pressure in patients with acute lung injury. JAMA. 2010;303:865-73.

25. Cavalcanti AB, Suzumura ÉA, Laranjeira LN, De Moraes PD, Damiani LP, Guimarães HP, et al. Effect of lung recruitment and titrated positive end-expiratory pressure (PEEP) vs low PEEP on mortality in patients with acute respiratory distress syndrome: a randomized clinical trial. JAMA. 2017;318:1335-45.

26. Serpa Neto A, Cardoso SO, Manetta JA, Pereira VGM, Esposito DC, Pasqualucci MDOP, et al. Association between use of lung-protective ventilation with lower tidal volumes. JAMA. 2012;308:1651-9.

27. Gattinoni L, Tonetti T, Cressoni M, Cadringher P, Herrmann $\mathrm{P}$, Moerer $\mathrm{O}$, et al. Ventilator-related causes of lung injury: the mechanical power. Intensive Care Med. 2016;42:1567-75.

28. Grasselli G, Zangrillo A, Zanella A, Antonelli M, Cabrini L, Castelli A, et al. (2020) Baseline characteristics and outcomes of 1591 patients infected with SARS-CoV-2 admitted to ICUs of the lombardy region, Italy. JAMA 
29. Vaschetto R, Longhini F, Persona P, Ori C, Stefani G, Liu S, et al. (2018) Early extubation followed by immediate noninvasive ventilation vs. standard extubation in hypoxemic patients: a randomized clinical trial. Intensive Care Med.

30. Cammarota G, Santangelo E, Lauro G, Verdina F, Boniolo E, De VN, et al. Esophageal balloon calibration during Sigh : a physiologic, randomized, cross-over study. J Crit Care. 2021;61:125-32.

31. Cammarota G, Verdina F, Santangelo E, Lauro G, Boniolo E, Tarquini R, et al. Oesophageal balloon calibration during pressure support ventilation: a proof of concept study. J Clin Monit Comput. 2020;34:1223.

32. Marini JJ. Dissipation of energy during the respiratory Cycle: Conditional importance of ergotrauma to structural lung damage. Curr Opin Crit Care. 2018;24:16-22.
33. Yoshida T, Amato MBP, Kavanagh BP. Understanding spontaneous vs. ventilator breaths: impact and monitoring. Intensive Care Med. 2018;44:2235-8.

34. Coppadoro A, Grassi A, Giovannoni C, Rabboni F, Eronia N, Bronco A, et al. Occurrence of pendelluft under pressure support ventilation in patients who failed a spontaneous breathing trial: an observational study. Ann Intensive Care. 2020;10.

Publisher's Note Springer Nature remains neutral with regard to jurisdictional claims in published maps and institutional affiliations. 